\title{
Development of an integrated methodology for fouling control in membrane bioreactors
}

\author{
[P. Gkotsis, A. Zouboulis, M. Mitrakas, D. Zamboulis, A. Tolkou, E. Peleka]
}

\begin{abstract}
The most serious drawback in wastewater treatment using membrane bioreactors (MBRs) is membrane fouling, which gradually leads to membrane permeability decrease and efficiency deterioration. This work is part of a research project that aims to develop an integrated methodology for membrane fouling control, using specific chemicals which enhance the coagulation and flocculation of compounds responsible for fouling, hence reducing biofilm formation on the membrane surface and limiting the fouling rate acting as a pre-treatment step. For this purpose, a pilotscale plant with fully automatic operation achieved by means of programmable logic controller (PLC) has been constructed and tested. The experimental set-up consists of four units: wastewater feed unit, bioreactor, membrane (side-stream) filtration unit and permeate collection unit. Synthetic wastewater $(\mathrm{BOD}=1000 \mathrm{mg} / \mathrm{L})$ was fed as the substrate for the activated sludge $(\mathrm{F} / \mathrm{M}=0.2 \mathrm{~kg} \quad \mathrm{BOD} / \mathrm{kg} \mathrm{MLVSS} \cdot \mathrm{d})$. The dissolved oxygen (DO) concentration of the aerobic tank was maintained in the range of $2-3 \mathrm{mg} / \mathrm{L}$ during the entire operation by using aerators below the membrane module. Backflushing steps of 1 min were performed periodically after $10 \mathrm{~min}$ of filtration. Membrane reversible and irreversible fouling was pre-assessed in terms of filterability tests and SMP (soluble microbial product) concentration measurements conducted in mixed liquor samples before and after the addition of commercial and composite coagulants. Membrane fouling results in increased treatment cost, due to high energy consumption and the need for frequent membrane cleaning and replacement. Due to the widespread application of MBR technology over the past few years, it becomes clear that the development of a methodology to mitigate membrane fouling is of paramount importance. The present work aims to develop an integrated technique for membrane fouling control in MBR systems and, thus, contribute to sustainable wastewater treatment.
\end{abstract}

Keywords - coagulation, membrane bioreactors, membrane fouling, pilot plant

P. Gotsis, A. Zouboulis, D. Zamboulis, A. Tolkou, E. Peleka Department of Chemistry, Aristotle University of Thessaloniki Greece

M. Mitrakas

Department of Chemical Engineering, Aristotle University of Thessaloniki Greece

\section{Introduction}

Membrane bioreactors have been widely used for municipal and industrial wastewater treatment [1-4], and recently for water reclamation as well [5]. Biomass separation membrane bioreactors, the most common type of MBR, are the amalgamation of a suspended growth reactor and a membrane (usually micro- or ultra-) filtration unit into a single process [6]. However, despite its widespread application and plentiful benefits (good effluent quality, high biomass concentration, reduced reactor volume and footprint), the MBR technology is constrained by membrane fouling which is regarded as the most serious drawback of process efficiency. Fouling leads to permeate flux decline which in turn decreases time intervals for membrane cleaning and replacement resulting both in higher operating costs. Therefore, most MBR studies aim to identify, investigate, control and model membrane fouling [7-9]. The most common methods to achieve this include the application of conventional physical or chemical methods, the optimal operation of the MBR process by permeate flux reduction and aeration increase, whereas more recent methods focus on: the (bio)chemical mixed liquor modification -such as the addition of specific chemicals (coagulants or other (re)agents) and the application of the Quorum Sensing (QS) method-, the application of ultrasound, electric field and ozone, or membrane surface modification. The latter may include physical coating/adsorption or grafting methods on the membrane surface, the use of patterned membranes, plasma treatment, chemical reaction on the membrane surface or surface modification with nanoparticles [10]. With specific regard to filtration of activated sludge in aerobic MBRs, it is widely recognized that the main foulants are the extracellular polymeric substances (EPS) [11-15] which can be classified into soluble EPS (sEPS or SMP, soluble microbial product) or bound EPS (bEPS), and constitute a matrix of high molecular weight molecules excreted from cells. Functions of the EPS matrix include aggregation of bacterial cells in flocs and biofilms, formation of a protective barrier around the bacteria, retention of water and adhesion to surfaces [16]. With its heterogeneous and changing nature, EPS can form a highly hydrated gel matrix in which microbial cells are embedded [17] and can thus help create a significant barrier to permeate flow in membrane processes. The objective of this work is the development of an integrated methodology for fouling control in a MBR system, which will enhance coagulation/flocculation process, thus reducing biofilm formation on the membrane surface and limiting the fouling rate acting as a co-treatment step. 


\section{Materials and Methods}

\section{A. Pilot-scale MBR system operation}

The pilot-scale MBR set-up consists of four units: wastewater feed unit, bioreactor, membrane (side-stream) filtration unit and permeate collection unit (Fig.1). By means of a peristaltic pump synthetic municipal sewage is led from the feed unit to the bioreactor, where the concentration of the dissolved oxygen is controlled and maintained by a dissolved oxygen meter in the range of $2-3 \mathrm{mg} / \mathrm{L}$. The effluent of the aeration tank passes through the membrane system, while part of the activated sludge returns to the bioreactor by means of another peristaltic pump. The air needed for the biomass and the cleaning of the membrane is supplied by an air compressor, the pressure of which is appropriately reduced to the desired value by means of an air pressure reducer. Gas and liquid flow rates are measured by means of gas and liquid flow meters, while level sensors are used in order to control the liquid level in the membrane unit. The permeate is withdrawn from the upper end of the membrane by means of a peristaltic pump, while a highresolution pressure transmitter is placed in the outlet of the membrane in order to record Transmembrane Pressure and, thus, indicate the extent of fouling during the process of filtration. The permeate collection unit is the final recipient of the produced permeate, a part of which is backwashed to the membrane filtration unit by means of a peristaltic pump. Membrane backflushing steps of $1 \mathrm{~min}$ were performed periodically after $10 \mathrm{~min}$ of filtration. It is noteworthy to highlight the automated operation of the pilot-scale MBR system: the operation of all peristaltic pumps, the dissolved oxygen meter, the level sensors and the electronic vacuum gauge is controlled by a programmable logic controller (PLC). The programming allows for the automatic backwashing of the membranes through pneumatic valves. In addition, the system can operate in a constant permeate flux and changing transmembrane pressure (TMP), and vice versa.

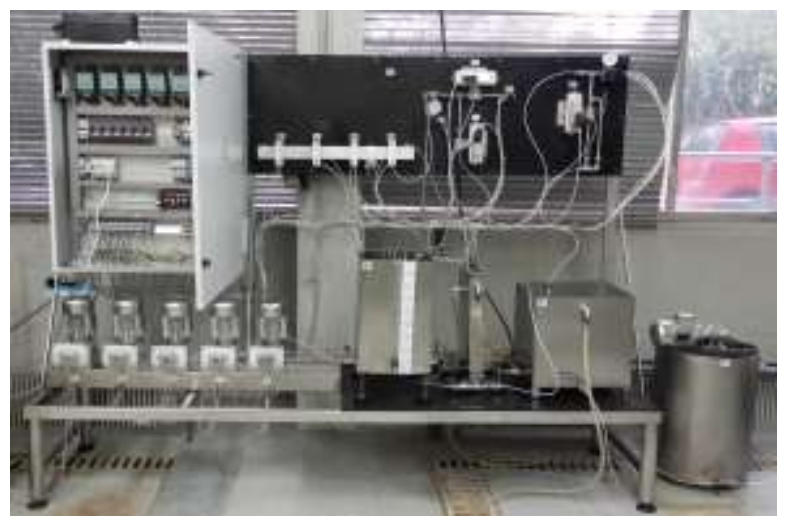

Figure 1. Pilot-scale MBR system

TABLE I. COMPOSITION OF SYNTHETIC MUNICIPAL WASTEWATER

\begin{tabular}{|c|c|}
\hline \multicolumn{2}{|c|}{ Synthetic Wastewater Composition } \\
\hline Substance & Concentration, $g / L$ \\
\hline
\end{tabular}

\begin{tabular}{|c|c|}
\hline Peptone & 1.6 \\
\hline Meat extract & 1.1 \\
\hline $\mathrm{K}_{2} \mathrm{HPO}_{4}$ & 0.28 \\
\hline $\mathrm{NaCl}$ & 0.07 \\
\hline $\mathrm{CaCl}_{2} \cdot 2 \mathrm{H}_{2} \mathrm{O}$ & 0.04 \\
\hline $\mathrm{MgSO}_{4} \cdot 7 \mathrm{H}_{2} \mathrm{O}$ & 0.02 \\
\hline
\end{tabular}

\section{B. Preparation of Coagulants}

Composite coagulants (PSiFAC-polyaluminum ferric silicate chloride) were produced at room temperature, according to a procedure proposed by Tolkou et al., 2014 [18], under various experimental conditions, and by using different ratios of components and (inorganic) polymerization modes. The used initial solutions were $0.5 \mathrm{M}$ $\mathrm{AlCl}_{3} \cdot 6 \mathrm{H}_{2} \mathrm{O}$ (Merck), $0.5 \mathrm{M} \mathrm{FeCl}_{3} \cdot 6 \mathrm{H}_{2} \mathrm{O}$ (Merck), $0.5 \mathrm{M}$ $\mathrm{NaOH}$ (Merck) -as the added base- and the prepared polysilicic acid solution (pSi), according to Tzoupanos et al., 2009 [19]. In particular, appropriate amount of ferric chloride solution was added to a solution of aluminum chloride, under vigorous stirring at the desired ratios of $\mathrm{Al} / \mathrm{Fe}$ and in the formed solution it was added the $\mathrm{pSi}$ at desired ratios of $\mathrm{Al}+\mathrm{Fe} / \mathrm{Si}$, followed by the polymerization of $\mathrm{Al}$ with the slowly (under magnetic stirring) addition of the appropriate amount of $\mathrm{NaOH}$ solution (PSiFAC copolymerization). To better compare our results, commercially available coagulants (e.g. ADIFLOC from ADIPAP, France) were tested as well.

\section{Bench-scale measurements}

Following a long acclimatization time (>40 days) provided to achieve steady-state conditions in the bioreactor (defined by high and stable BOD removal >95\%), membrane fouling was pre-assessed in terms of filterability tests and SMP (soluble microbial product) concentration measurements conducted in mixed liquor samples before and after the addition of commercial and composite coagulants.

A well-established parameter used to determine sludge filterability is time to filter method (TTF). TTF is determined by using an apparatus shown in Fig. 2. A 90-mm Buchner funnel is used with Whatman \#1, \#2 or equivalent filter papers. After pouring $200 \mathrm{ml}$ of mixed liquor (after the addition of the coagulant), the time required to obtain 100 $\mathrm{mL}$ of filtrate is measured at the vacuum pressure of 510 mbar.

The Phenol-Sulfuric Acid Method [20] is the most widely used colorimetric method for the determination of carbohydrate concentration in aqueous solutions. The basic principle of this method is that carbohydrates, when dehydrated by reaction with concentrated sulfuric acid, produce furfural derivatives. Further reaction between furfural derivatives and phenol develops detectible color. The standard procedure of this method is as follows: $1 \mathrm{~mL}$ aliquot of a carbohydrate solution is mixed with $1 \mathrm{~mL}$ of $5 \%$ aqueous solution of phenol in a test tube. Subsequently, 5 $\mathrm{mL}$ of concentrated sulfuric acid is added rapidly to the mixture. After allowing the test tubes to stand for $10 \mathrm{~min}$, they are vortexed for $30 \mathrm{~s}$ and placed for $20 \mathrm{~min}$ in a water 
Proc. of the Second Intl. Conf. on Advances in Bio-Informatics and Environmental Engineering - ICABEE 2015

Copyright $($ Institute of Research Engineers and Doctors, USA .All rights reserved.

ISBN: 978-1-63248-043-9 doi: 10.15224/ 978-1-63248-043-9-30

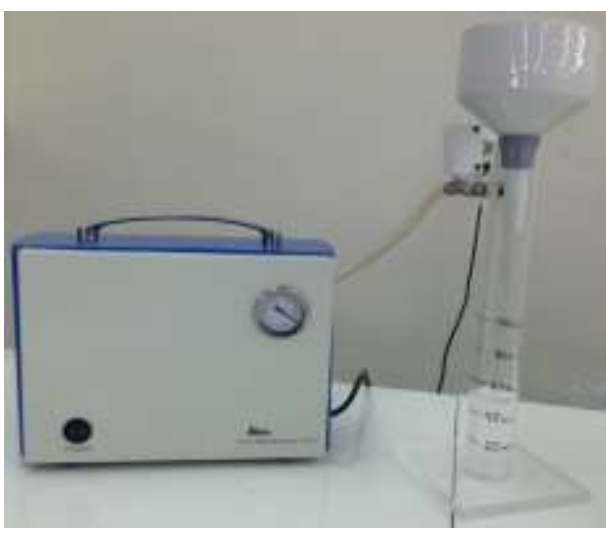

Figure 2. Time to filter (TTF) test equipment.

bath at room temperature for color development. Then, light absorption at $490 \mathrm{~nm}$ is recorded on a spectrophotometer. Reference solutions are prepared in identical manner as above, except that the $1 \mathrm{~mL}$ aliquot of carbohydrate is replaced by DDI water. A Hitachi UV/Vis spectrophotometer was used for this purpose.

\section{Results and Discussion}

\section{A. Fouling pre-assessment}

The use of chemical additives for studying fouling phenomena in MBRs usually include the inline addition of the former in the bioreactor or the filtration tank while the most common criterion for fouling assessment is TMP increase or flux decline as a function of time. This study aims to develop an integrated methodology for fouling control in a MBR system, which enhance coagulation/flocculation process, thus reducing biofilm formation on the membrane surface and limiting the fouling rate acting as a co-treatment step. Before the inline coagulant addition in the pilot-scale MBR system, membrane fouling is pre-assessed in terms of filterability tests (indicative of reversible or temporary fouling) and SMP concentration measurements (indicative of irreversible or permanent fouling) conducted in mixed liquor samples before and after the addition of commercial and composite coagulants (TABLE II). Fig. 3 shows the application of TTF method to compare the effect of two different coagulants on sludge filterability improvement. The results clearly indicate that the commercial ADIFLOC KD453 improves sludge filterability and reduces SMP concentration as well (TABLE III).
TABLE II. INDICATIVE COMMERCIAL AND COMPOSITE COAGULANTS USED

\begin{tabular}{|c|c|}
\hline TYPE & DESCRIPTION \\
\hline \multicolumn{2}{|r|}{ Commercial } \\
\hline \multicolumn{2}{|r|}{$\underline{\text { Organic }}$} \\
\hline FO4350SSH & CPE-cationic \\
\hline Centifloc $1407 \mathrm{CH}$ & CPE-cationic \\
\hline ADIFLOC KD453 & CPE-cationic \\
\hline \multicolumn{2}{|r|}{$\underline{\text { Inorganic }}$} \\
\hline PAC 10 & $5 \% \mathrm{Al}$ \\
\hline PAC 16 & $8 \% \mathrm{Al}$ \\
\hline PAC 18 & $16 \% \mathrm{Al}$ \\
\hline \multicolumn{2}{|r|}{ Composite } \\
\hline \multicolumn{2}{|r|}{ Al based } \\
\hline PSiFAC $_{1.5-10.15}$ & $\left(\mathrm{Al}+\mathrm{FeCl}_{3}\right)+\mathrm{pSi}+\mathrm{NaOH}$ \\
\hline $\mathrm{PSiF}^{2} \mathrm{~F}^{3} \mathrm{AC}_{1.5-10-15}$ & $(\mathrm{Al}+\mathrm{Fe}(\mathrm{II}) / \mathrm{Fe}(\mathrm{III}))+\mathrm{pSi}+\mathrm{NaOH}$ \\
\hline PSiCAF $_{\text {PAC18-10-15 }}$ & $\left(\mathrm{PAC} 18+\mathrm{FeCl}_{3}\right)+\mathrm{pSi}$ \\
\hline \multicolumn{2}{|r|}{ Fe based } \\
\hline PFSiC $_{1.5-15}$ & $\mathrm{FeCl}_{3}+\mathrm{pSi}+\mathrm{NaOH}$ \\
\hline $\mathrm{PFSiC}_{1.5-20}$ & $\mathrm{FeCl}_{3}+\mathrm{pSi}+\mathrm{NaOH}$ \\
\hline $\mathrm{PFSiC}_{2-15}$ & $\mathrm{FeCl}_{3}+\mathrm{pSi}+\mathrm{NaOH}$ \\
\hline
\end{tabular}

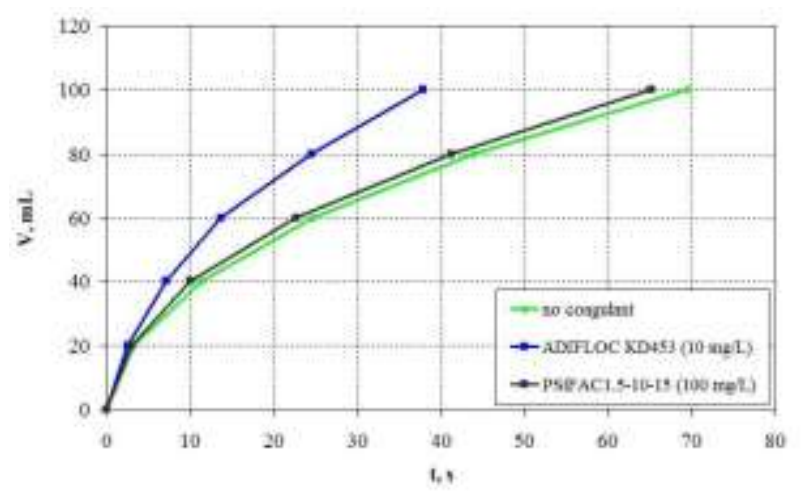

Figure 3. Effect of different coagulants on sludge filterability.

$\begin{array}{llll}\text { TABLE III. EFFECT OF } & \text { COAGULANTS ON } & \text { SMP }\end{array}$ CONCENTRATION

\begin{tabular}{|c|c|c|}
\hline & $\begin{array}{c}\text { SMP concentration in } \\
\text { TTF permeate, } \mathbf{~ m g} / \mathbf{L}\end{array}$ & SMP removal, \% \\
\hline Blank (no coagulant) & 25.18 & - \\
\hline ADIFLOC KD453 & 10.09 & 60 \\
\hline PSiFAC $_{1.5-10.15}$ & 15.91 & 37 \\
\hline
\end{tabular}




\section{B. Pilot-scale MBR efficiency}

The pilot-scale MBR operated at a SRT of 20 days dealing with a challengingly high strength synthetic municipal wastewater in terms of organic content $(\mathrm{BOD}=1000 \mathrm{mg} / \mathrm{L})$. Permeate samples were analyzed for the following parameters: biochemical oxygen demand (BOD), chemical oxygen demand (COD), total nitrogen (TN), ammonium $\left(\mathrm{NH}_{4}^{+}-\mathrm{N}\right)$, nitrate $\left(\mathrm{NO}_{3}^{-}-\mathrm{N}\right)$, total phosphorus (TP), phosphate $\left(\mathrm{PO}_{4}^{3-}-\mathrm{P}\right)$, total organic carbon (TOC), UV absorbance at $254 \mathrm{~nm}$, electrical conductivity and turbidity. Effluent samples were collected at the same day of the week and the same time of the day to minimise the impact of daily or weekly variations. As it can be seen in Fig. 4 the pilotscale MBR supports high BOD and COD removal (>95\%).

The TMP was closely monitored while the membrane flux was set at 5.3 LMH (Fig. 5). The DO concentration of the aerobic tank was maintained in the range of $2-3 \mathrm{mg} / \mathrm{L}$ during the entire operation by using aerators below the membrane module. Backflushing steps of 1 min were performed periodically after $10 \mathrm{~min}$ of filtration. Evidence from TMP change suggests that low temperature favors TMP rise.

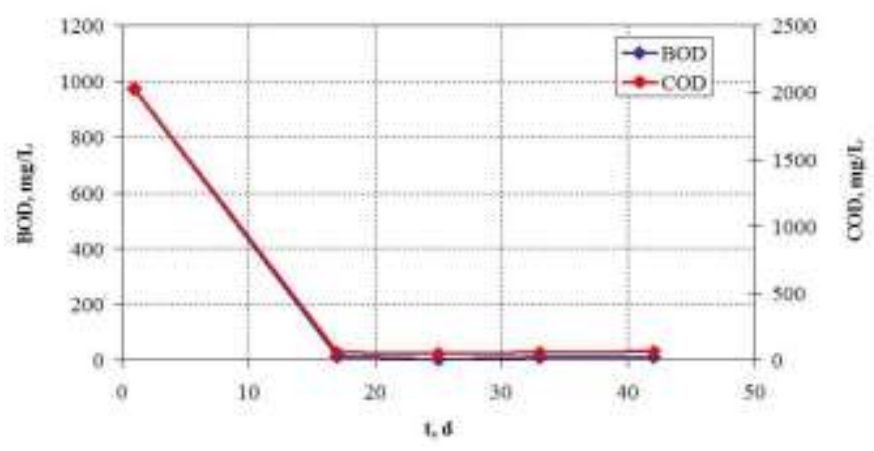

Figure 4. Organic removal efficiency in the pilot-scale MBR.

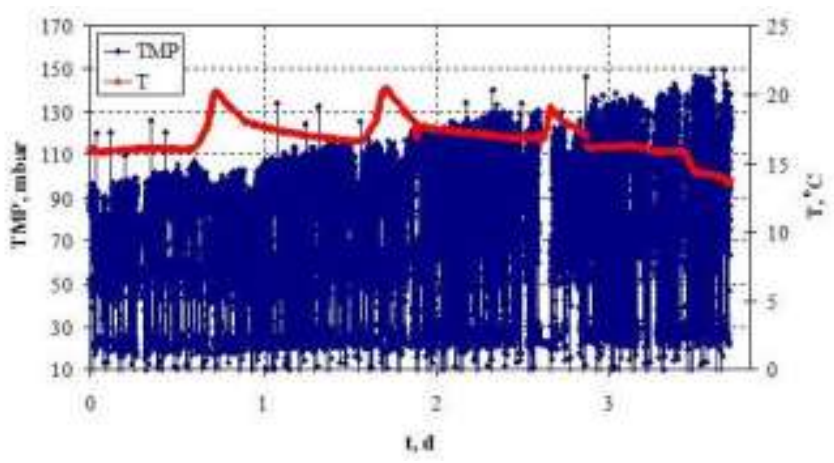

Figure 5. TMP and temperature as a funcion of time.

\section{Conclusions}

This study aims to develop an integrated methodology for fouling control in a MBR system, which will enhance coagulation/flocculation process, thus reducing biofilm formation on the membrane surface and limiting the fouling rate acting as a co-treatment step. Before the inline coagulant addition in the pilot-scale MBR system, membrane fouling is pre-assessed in terms of filterability tests (indicative of reversible or temporary fouling) and SMP concentration measurements (indicative of irreversible or permanent fouling) conducted in mixed liquor samples before and after the addition of commercial and composite coagulants. Preliminary tests demonstrate that coagulant addition clearly enhances sludge filterability and reduces significantly SMP while, at the same time, the pilot-scale MBR system exhibits remarkable behaviour in terms of organic removal (> 95\%). The most serious drawback in wastewater treatment using MBRs is membrane fouling, which gradually leads to membrane permeability decrease and efficiency deterioration. This results in increased treatment cost, due to high energy consumption and the need for frequent membrane cleaning and replacement. Due to the widespread application of MBR technology over the past few years, it becomes clear that the development of a methodology to mitigate membrane fouling is of paramount importance. The present work aims to develop an integrated technique for membrane fouling control in MBR systems and, thus, contribute to sustainable wastewater treatment.

\section{Acknowledgment}

The financial support through the co-Financed by the European Union and the Greek State programme EPAN-II/ ESPA: 'SYNERGASIA II' Project FOUL-MEM, (11SYN-81084) is gratefully appreciated.

\section{References}

[1] K. Brindle, T. Stephenson, "The application of membrane biological reactors for the treatment of wastewaters in Biotechnology and Bioengineering", vol. 49, 1996, pp. 601-610.

[2] R. S. Trussell, S. Adham, P. Gagliarado, R. Merlo, R. R. Trussel, "Application of MBR Technology for Wastewater Treatment," in Proceedings of the $73^{\text {rd }}$ Annual Water Environment Federation Conference, October 14-18, Anaheim, CA., 2000.

[3] L. Van Dijk, G. C. G Roncken, "Membrane bioreactor for wastewater treatment: the state of the art and new developments," in Water Science and Technology, vol. 35, 1997, pp. 35-41.

[4] A. Tolkou, A. Zouboulis, P. Samaras, "The incorporation of ceramic membranes in MBR systems for wastewater treatment: Advantages and patented new developments", Recent Patents on Engineering, 8(1), 2014, pp. 24-32.

[5] N. Cicek, J. P. Franco, M. T. Suidan, V. Urbain, "Using a membrane bioreactor to reclaim wastewater", in Journal of American Water Works Association, vol. 76, 1998, p. 356.

[6] T. Stephenson, S. Judd, B. Jefferson, K. Brindle, Membrane Bioreactors for Wastewater Treatment, IWA Publishing, London 2000.

[7] K. Akamatsu, W. Lu, T. Sugawara, S.-I. Nakao, "Development of a novel fouling suppression system in membrane bioreactors using an intermittent electric field," in Water Research, vol. 44, 2010, pp. 825830 .

[8] V. Iversen, R. Mehrez, R. Y. Horng, C. H. Chen, F. Meng, A. Drews, "Fouling mitigation through flocculants and adsorbents addition in membrane bioreactors: comparing lab and pilot studies", in Journal of Membrane Science, vol. 345, 2009b, pp. 21-30. 
Proc. of the Second Intl. Conf. on Advances in Bio-Informatics and Environmental Engineering - ICABEE 2015

Copyright $@$ Institute of Research Engineers and Doctors, USA .All rights reserved.

ISBN: 978-1-63248-043-9 doi: 10.15224/ 978-1-63248-043-9-30

[9] F. Meng, S.-R. Chae, A. Drews, M. Kraume, H.-S. Shin, F. Yang, "Recent advances in membrane bioreactors (MBRs): Membrane fouling and membrane material," in Water Research, vol. 43, 2009, pp. 1489-1512.

[10] P. K. Gkotsis, D. Ch. Banti, E. N. Peleka, A. I. Zouboulis, P. E. Samaras, "Fouling issues in membrane bioreactors (MBRs) for wastewater treatment: major mechanisms, prevention and control strategies," in Processes, vol. 2, 2014, pp. 795-866.

[11] L. Z. Stec, R. W. Field, "The effect of the extracellular matrix on the microfiltration of microorganisms," in Proceedings of Euromembrane '95, University of Bath, Bath, UK, II-402-405, 1995.

[12] I. S. Chang, C. H. Lee, "Membrane filtration characteristics in membrane-coupled activated sludge system-the effect of physiological states of activated sludge on membrane fouling," in Desalination, vol. 120, 1998, pp. 221-233.

[13] H. Nagaoka, S. Yamanishi, A. Miya, "Modelling of biofouling by extracellular polymers in a membrane separation activated sludge system," in Water Science and Technology, vol. 38, 1998, pp. 497504.

[14] H. S. Nagaoka, S. Yamanishi, A. Miya, "Influence of organic loading rate on membrane fouling in membrane separation activated sludge process," in Proceedings of Membrane Technology in Environmental Management, Nov 1-4, Tokyo, Japan, 242-249, 1999.

[15] Banti D., Samaras P., Zouboulis A., Mitrakas M., "Analysis of the characteristics of Extracellular Polymeric Substances (EPS) of activated sludge mixed liquor as potential foulants in MBRs", 3rd International Workshop "MBR for the Next Generation III (Istanbul, Turkey, 17-18/12/2013), pp. 13-15.

[16] C. S. Laspidou, B. E. Rittmann, "A unified theory for extracellular polymeric substances, soluble microbial products and active and inert biomass," in Water Research, vol. 36, 2002, pp. 2711-2720.

[17] P. H. Nielson, A. Jahn, Extraction of EPS, Wingender, Neu, Flemming, Eds.; Springer-Verlag, Berlin, 1999.

[18] A. K. Tolkou, A. I. Zouboulis, "Synthesis and coagulation performance of composite poly-aluminum-ferric-silicate-chloride coagulants in water and wastewater," in Desalination and Water Treatment, vol. 53(12), 2014, pp. 3309-3318.

[19] A. I. Zouboulis, N. D. Tzoupanos, "Polyaluminium silicate chloride A systematic study for the preparation and application of an efficient coagulant for water or wastewater treatment", Journal of Hazardous Materials, vol. 162, 2009, pp. 1379- 1389.

[20] M. DuBois, K. Gilles, J. Hamilton, P. Rebers, F. Smith, "Colorimetric method for determination of sugars and related substances," in Analytical Chemistry, 28(3), 1956, pp. 350-356. 